\title{
Hyaluronic acid (HA) presentation as a tool to modulate and control the receptor-mediated uptake of HA-coated nanoparticles
}

\author{
Abdulaziz Almalik ${ }^{a}$, Shima Karimi ${ }^{\text {b,c }}$, Sihem Ouasti ${ }^{\text {b,1 }}$, Roberto Donno ${ }^{\text {, }}$, \\ Christine Wandrey ${ }^{\mathrm{c}}$, Philip J. Day ${ }^{\mathrm{d}}$, Nicola Tirelli ${ }^{\mathrm{b}, \mathrm{e}, *}$

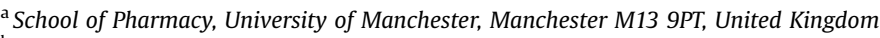 \\ ${ }^{\mathrm{b}}$ School of Biomedicine, Institute of Inflammation and Repair, University of Manchester, Manchester M13 9PT, United Kingdom \\ ${ }^{c}$ Laboratoire de Médecine Régénérative et de Pharmacobiologie, Ecole Polytechnique Fédérale de Lausanne, 1015 Lausanne, Switzerland \\ ${ }^{\mathrm{d}}$ Institute of Population Health and Manchester Institute of Biotechnology, University of Manchester, Manchester M13 9PT, United Kingdom \\ ${ }^{\text {e }}$ School of Materials, University of Manchester, Manchester M13 9PT, United Kingdom
}

\section{A R T I C L E I N F O}

\section{Article history:}

Received 29 January 2013

Accepted 25 March 2013

Available online 21 April 2013

\section{Keywords:}

Nanoparticles

CD44

Hyaluronic acid

Alginate

Endocytosis

\begin{abstract}
A B S T R A C T
The natural turnover of free hyaluronic acid (HA) is predominantly based on its CD44-mediated internalisation in leukocytes. In a phagocytic cell model (RAW 264.7 murine macrophages) we here provide conclusive evidence that this receptor-mediated mechanism endocytosis is responsible also of the uptake of materials where HA is used as a coating agent, in this case chitosan/triphosphate nanoparticles on whose surface HA is electrostatically adsorbed. Alginate-coated nanoparticles were used as a control and they appeared to undergo a qualitatively similar endocytic process, which was mediated by a different scavenging receptor yet to be identified. In this general picture, an important, modulating role appears to be played by how receptors can cluster around individual nanoparticles. The CD44 slow representation (24-48 h) enforces a limit in the amount of available HA internalisation receptors; therefore a higher affinity, and hence a higher degree of clustering, would yield a lower number of internalised nanoparticles. HA presentation can be varied by acting on nanoparticle structure/ morphology, and our data suggest that a better presentation may be linked to both higher affinity and lower capacity/uptake rate. Paradoxically, this result would suggest that particles with a lower affinity for CD44 may allow a more efficient HA-mediated delivery of payloads.
\end{abstract}

(c) 2013 Elsevier Ltd. All rights reserved.

\section{Introduction}

Hyaluronic acid (HA), a major glycosoaminoglycan (GAG) constituent of extracellular matrices, is increasingly seen as a potential agent to target conditions (e.g. several solid tumours) characterised by the overexpression of its main receptor, CD44 [1,2]. A variety of HA-based carriers have been used for the purpose of targeting tumoural cells, e.g. HA-butirrate [3], HA-paclitaxel [4] conjugates, self-assembled [5], PLGA-based [6] or disulfide cross-linked nanoparticles [7], and PEGylated HA derivatives [8]. This field has been recently reviewed by Choi et al. [9] and Ossipov et al. [10]. In the majority of cases, the role of CD44 in the internalisation of HA-based carrier structures is inferred from the preferential

\footnotetext{
* Corresponding author. School of Biomedicine, Institute of Inflammation and Repair, University of Manchester, Manchester M13 9PT, United Kingdom. E-mail address: Nicola.Tirelli@manchester.ac.uk (N. Tirelli).

1 Current address: Faculty of Life Sciences, NUS Center for Bioimaging Sciences (CBIS), National University of Singapore, Singapore 117546, Singapore.
}

internalisation in CD44 (over)expressing cell lines: for example, from the comparison of MDA-MB-231 vs. ZR-75-1 breast cancer cell lines [11], of HepB3 and HepG2 hepatoma cell lines [12], or of SCC7 squamous cell carcinoma cells and fibroblasts or HA-saturated cells [5]. Two important caveats exist: a) the slow representation of CD44 and hence its ease of saturation is a cause of concern, since, as we have recently shown, this drawback cannot be circumvented by the addition of ancillary internalisation ligands [13]; b) CD44 is heavily expressed not only by tumoral cells, but also by inflammatory cells [14], e.g. playing a major role in the clearance of apoptotic cells by macrophages [15]; the expression of CD44 by ubiquitous cells such as leukocytes may be seen as a problem, since it would inherently reduce the targeting efficiency of tumoral cells, but may also open new avenues by allowing to target (activated) leukocytes.

A yet unanswered question is whether inflammatory cells would be able to recognise HA when it is present on the surface of a nano-carrier, since its binding to leucocyte CD44 is affected by several morphological variables, such as HA molecular weight 
[16] and spatial arrangement (e.g. HA cables vs. pericellular coats $[17,18])$, or the possibility of receptor clustering around it [19]. Indeed the mode of ligand presentation is a major determinant of the uptake of nanocarriers, as it has been demonstrated also using coarse-grained simulations [20]. Previous literature studies have suggested that HA-coated nanoparticles can be internalised in a receptor-mediated fashion $[21,22]$, but a final proof is still lacking. Further, if we hypothesise that internalisation is mediated by a slowly represented receptor, the extent of its clustering around individual nanoparticles determines their uptake rate and affinity: high level of clustering would correspond to high affinity, but this will limit the overall capacity, thus determining an apparently slow uptake (Scheme 1). In turn, the degree of receptor clustering would depend on nanoparticle dimension and on the accessibility of HA residues and their individual affinity for the receptors.

In this study, we have used the polyelectrolyte complexation of chitosan with triphosphate (TPP) to produce nanoparticles, which were then employed as a cationic core to complex HA and deliver HA-coated chitosan/TPP nanoparticles (CS-TPP//HA). The electrostatic adsorption of HA on CS-TPP nanoparticles can be modulated by several variables of the preparative process [23], possibly influencing its mode of presentation and its interactions with cell receptors. Therefore, we have investigated the effect of chitosan molecular weight and of two different preparative methods on the toxicity, internalisation kinetics and mechanism of CS-TPP//HA nanoparticles in a phagocyte model (RAW 264.7 macrophages). In addition, nanoparticles coated by an anionic, non-CD44 binding polysaccharide of similar size (alginate, CS-TPP//Alg) were used as a control.

In terms of molecular weight, we have employed chitosan with $\overline{M_{v}}=684 \mathrm{kDa}$ ( $\sim 85 \%$ deacetylated), $325 \mathrm{kDa}$ ( $\sim 92 \%$ deacetylated) and $25 \mathrm{kDa}(\sim 85 \%$ deacetylated, produced through nitrite controlled degradation of the highest molecular weight). Chitosan size is likely to influence the internal structure of the nanoparticles: higher molecular weight is likely to be less efficiently cross-linkable and therefore to produce more porous particles (larger dimensional variations in response to changes in ionic strength); on its turn, this can lead to better HA penetration as opposed to surface adsorption, therefore influencing its presentation to cell receptors.

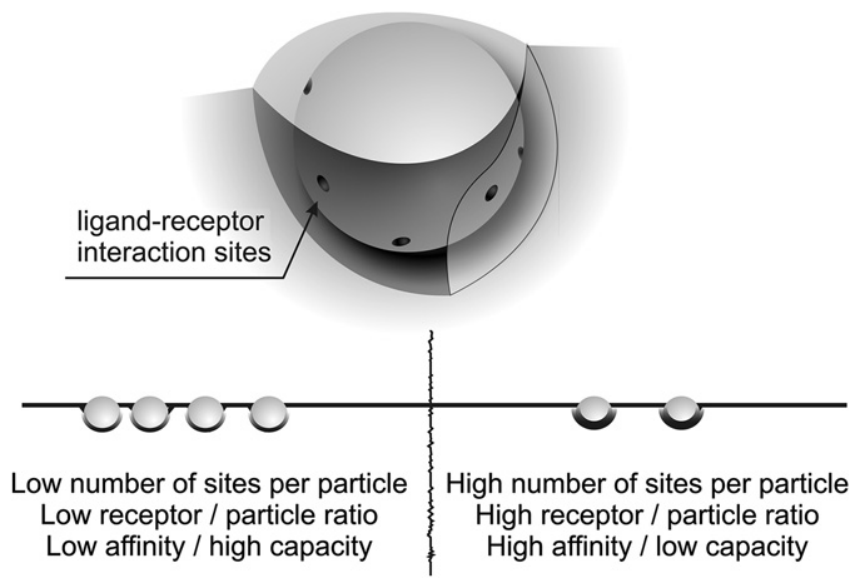

Scheme 1. Under conditions of slow receptor representation, the amount of available receptors is a crucial factor to determine the uptake kinetics of e.g. an HA-coated nanoparticle. A limited number of interaction sites, e.g. because of poor presentation of HA, would allow the internalisation of a larger amount of less strongly bound nanoparticles (bottom left); on the contrary, strong interactions due to the clustering of many receptors around each nanoparticle may lead to a small number of nanoparticles being internalised (bottom right).
Table 1

Key differences between preparative methods A and B.

\begin{tabular}{lllll}
\hline & Addition of TPP & $\begin{array}{l}\mathrm{pH} \text { during } \\
\text { CS/TPP } \\
\text { complexation }\end{array}$ & $\begin{array}{l}\text { pH during } \\
\text { coating }\end{array}$ & $\begin{array}{l}\text { Removal of } \\
\text { excess of } \\
\text { coating agent } \\
\text { via dialysis }\end{array}$ \\
\hline Method A & $\begin{array}{l}\text { Injection into } \\
\text { chitosan solution } \\
\text { Dethod B }\end{array}$ & 5.0 & 5.0 & Yes \\
\hline
\end{tabular}

In terms of preparative method, we have followed two procedures, whose key differences are summarised in Table 1.

Method A was optimised in a previous study [23] and implemented with chitosan of $\overline{M_{v}}=684,325$ and $24 \mathrm{kDa}$; by using the same $\mathrm{pH}=5$ for all solutions, it allows to minimise the influence of different mixing conditions, while by minimising the charge density on both cationic and anionic components, it provides the conditions for a likely slower but more controlled complexation. On the contrary, method B (in this case implemented with chitosan of $\overline{M_{v}}=325 \mathrm{kDa}$ ) provides a higher charge density to chitosan during TPP complexation and to the anionic coating agent during nanoparticle coating; therefore, in this method the phenomena of polyelectrolyte complexation are likely to occur faster. Further, the different mode of addition of TPP (injection of the liquid into chitosan solution in method A vs. its dropwise addition in method B) may result in different mixing kinetics and thus contributes to structural differences in the nanoparticle structure. Last, method B is performed under fully aseptic conditions and the nanoparticles can be directly applied to cell experiments, while in method A they are purified by dialysis and then sterile-filtered; method $B$ is therefore more rapid and robust with less variables being introduced, and it is therefore suited for the preparation of the nanoparticle dispersion immediately before administration (advantageous for sensitive payloads and because controlled storage conditions are not required) but the presence of non-adsorbed HA or alginate may affect the results.

\section{Materials and methods}

2.1. Materials

Middle-viscosity chitosan of $\overline{M_{v}}=684 \mathrm{kDa}$ (Mark-Houwink coefficients: ( $K=1.57 \times 10^{-5} \mathrm{~L} \mathrm{~g}^{-1}$ and $a=0.79$ ) [24]) and degree of deacetylation $85 \%$ was purchased from Sigma (Sigma-Aldrich, Gillingham, UK). Lower molecular weight chitosan $\left(\overline{M_{v}}=25 \mathrm{kDa}\right)$ was obtained by oxidative degradation of middle-viscosity chitosan $(1 \% w / v$ in $0.1 \mathrm{M} \mathrm{HCl})$ using $3 \mathrm{~mm}$ sodium nitrite. All chitosan samples were purified as described in previous reports. Chitosan of $\overline{M_{v}}=325 \mathrm{kDa}$ (degree of deacetylation $92 \%)$, sodium alginate $\left(\overline{M_{v}}=400 \mathrm{kDa}\right)$ and hyaluronic acid (HA; $\overline{M_{v}}=360 \mathrm{kDa}$ ) were provided by Medipol (Medipol SA, Ecublens, Switzerland).

Sodium triphosphate pentabasic (TPP), dimethyl sulfoxide (DMSO) and rhodamine B isothiocyanate (RITC) were purchased from Sigma-Aldrich (Gillingham, UK). [3-(4,5-Dimethylthiazol-2-yl)-5-(3-carboxymethoxyphenyl)-2-(4-sulfophenyl)-2Htetrazolium] (MTS) kit was purchased from Promega (Madison, WN, USA).

RAW 264.7 macrophages (ECACC, UK), Dulbecco's modified eagle medium (DMEM), the quantipro BCA assay kit, Triton X-100, antibiotic-antimitotic solution, sodium pyruvate, D-glucose, $4^{\prime}, 6$-diamidino-2-phenylindole (DAPI) and endocytosis portals inhibitors (cytochalasin D, filipin, 5-(N-ethyl-N-isopropyl)amiloride (EIPA), nocodazole, chloropromazine, bafilomycin $\mathrm{A} 1$ and sodium azide) were purchased from Sigma-Aldrich. Foetal bovine serum (FBS), LysoTracker Green DND-26, Lglutamine and anti-fade mounting gel were purchased from Invitrogen (Paisley, UK). Monoclonal antibody anti-CD44 [KM81] and paraformaldehyde were respectively brought from Abcam (Cambridge, UK) and VWR (Lutterworth, UK).

\subsection{Fluorescent labelling of chitosan}

An amount of chitosan corresponding to $0.48 \mathrm{mmol}$ of amine groups ( $100 \mathrm{mg}$ for CS684) were dissolved in $18 \mathrm{~mL}$ of $0.10 \mathrm{~m}$ acetic acid solution and the $\mathrm{pH}$ was then adjusted to 4 with $0.1 \mathrm{~m} \mathrm{NaOH} .10 \mathrm{mg}$ of RITC ( $0.019 \mathrm{mmol}$ of isothiocyanate groups) dissolved in $2 \mathrm{~mL}$ of DMSO were added slowly to the chitosan solution using a 
dropping funnel. The reaction was left under stirring for $12 \mathrm{~h}$ protected from light. The reaction mixture was then diluted with $20 \mathrm{~mL}$ of deionised water and dialysed against deionised water ( $\mathrm{pH}=6.5$ ) using an RC dialysis membrane of MWCO $10 \mathrm{kDa}$ (SpectraPor, Spectrum Laboratories Inc., Rancho Dominguez, CA, USA) until the conductivity and $\mathrm{pH}$ values of the waste water reached the values of pure water. The sample was then freeze-dried and stored at $4{ }^{\circ} \mathrm{C}$. The degree of functionalisation was determined by measuring the fluorescence intensity of the RITC-chitosan solution, using a calibration of fluorescein $\left(\lambda_{\mathrm{ex}}=540 \mathrm{~nm} ; \lambda_{\mathrm{em}}=620 \mathrm{~nm}\right)$. Typically, $1.2-1.7 \%$ mol of D-glucosamine units were derivatised.

\subsection{Preparation of nanoparticles}

\subsubsection{Method $A$}

A $0.069 \%$ wt. RITC-labelled chitosan solution was prepared by dissolving purified RITC-labelled chitosan in $4.6 \mathrm{~mm} \mathrm{HCl}$. The $\mathrm{pH}$ was adjusted to 5 by the addition of appropriate volumes of $0.1 \mathrm{~m} \mathrm{NaOH}$. The solution was kept under magnetic stirring overnight and sonicated for $40 \mathrm{~min}$. TPP was prepared as a $0.1 \%$ wt. solution in deionised water, correcting the $\mathrm{pH}$ to 5 using appropriate volumes of $\mathrm{HCl} 0.1 \mathrm{~m}$. Both solutions were filtered through a $0.22 \mu \mathrm{m}$ pore size filter. The nanoparticles were prepared by addition of the TPP solution $0.1 \%$ wt. to the chitosan solution in a 1:9 TPP to chitosan mass ratio, e.g. for a final volume of $3 \mathrm{~mL}$ of nanoparticle solution, $214 \mu \mathrm{L}$ of TPP solution is added to $2786 \mu \mathrm{L}$ of chitosan solution, where the final concentrations of chitosan and TPP are 0.064 and $0.0071 \%$ wt., respectively. The complexation was carried under magnetic agitation (750 rpm), for $30 \mathrm{~min}$ at $25^{\circ} \mathrm{C}$ The final dispersion was sonicated for $40 \mathrm{~min}$ and then left undisturbed for additional $16 \mathrm{~h}$. Then the nanoparticle dispersion was dialysed against deionised water (MWCO $1000 \mathrm{kDa}$ ) before being surface decorated by HA (360 kDa) or sodium alginate $(400 \mathrm{kDa})$. For the surface coating process, $5 \mathrm{~mL}$ of a $0.025 \% \mathrm{wt}$. dispersion of CS-TPP nanoparticles in $100 \mathrm{~mm}$ acetate buffer at $\mathrm{pH}=5$ were added under vigorous magnetic stirring ( $30 \mathrm{~min}, 1200 \mathrm{rpm}$ ) to an equal volume of HA or sodium alginate both at a concentration of $0.15 \%$ wt. in the same buffer. The dispersions were then dialysed against deionised water $(\mathrm{pH}=6.5$, membranes with MWCO $1000 \mathrm{kDa})$.

\subsubsection{Method $B$}

The preparative method is based on a patented aseptic process [25]. RITC labelled chitosan $(325 \mathrm{kDa}$ ) was dissolved in deionised water (final concentration is $0.1 \% w / v)$ by the addition of $1 \mathrm{M} \mathrm{HCl}$ until the $\mathrm{pH}$ was stabilised below 4 . The dispersion was kept under magnetic stirring until complete dissolution. TPP $0.1 \%$ ( $w)$ $v$ ) in deionised water at $\mathrm{pH} \approx 6.5$ was added dropwise to the chitosan solution, in a 1:9 TPP to chitosan mass ratio while keeping the $\mathrm{pH}$ under 4 by the addition of proper volumes of $0.1 \mathrm{~m} \mathrm{HCl}$. The suspension was kept under stirring for an hour and then diluted with deionised water at a 1:1 $(v / v)$ ratio. The dispersion was then added dropwise to $0.1 \%(w / v)$ sterile filtered aqueous HA or alginate solutions at a volume ratio of $1: 1(v / v)$ under vigorous agitation. $0.1 \mathrm{~m} \mathrm{NaOH}$ was used to adjust the $\mathrm{pH}$ of the final nanoparticle suspension to 7.2. Finally, the suspension was kept under magnetic stirring for one additional hour at room temperature.

\subsection{Physico-chemical characterisation}

Hydrodynamic diameter (Z-average size), size polydispersity (PDI) and zeta potential measurements were always performed on three independent samples at a temperature of $25{ }^{\circ} \mathrm{C}$ using a Zetasizer Nano ZS instrument (Model ZEN3600, Malvern Instruments Ltd., UK) equipped with a solid state HeNe laser $(\lambda=633 \mathrm{~nm})$ and measuring at a scattering angle of $173^{\circ}$.

Atomic force microscopy (AFM) images were acquired at $25{ }^{\circ} \mathrm{C}$ in air using a Molecular Force Probe 3D AFM (MFP-3D, Asylum Research, Santa Barbara, CA). Silicon cantilever (model NP-S10, Bruker) with a nominal spring constant, tip radius, tip height and resonance frequency, of $0.06 \mathrm{~N} / \mathrm{m}, 20 \mathrm{~nm}, 2.5-8 \mu \mathrm{m}, 18 \mathrm{kHz}$ respectively, was used. Contact mode images of several regions were acquired (512 $\times 512$ pixels per inch), at a scan frequency of $1 \mathrm{~Hz}$ and a gain of 10 .

\subsection{Cellular interactions of nanoparticles}

\subsubsection{General cell culture}

RAW 264.7 macrophages were maintained as a semi-adherent cell culture in standard conditions for cell culture $\left(37{ }^{\circ} \mathrm{C}, 5 \% \mathrm{CO}_{2}\right.$, in humidified atmosphere) in Dulbecco's modified eagle minimal essential medium (DMEM) supplemented with $10 \%$ heat-inactivated foetal bovine serum (FBS), $2 \times 10^{-3} \mathrm{~m}$ glutamine, $100 \mathrm{U} \mathrm{mL}^{-1}$ penicillin and $100 \mathrm{U} \mathrm{mL}^{-1}$ streptomycin. Cells were detached by scrapping and adjusted to the required concentration of viable cells, by counting in a haemocytometer.

\subsubsection{Cell viability assays}

RITC-labelled chitosan was employed in the preparation of nanoparticles through both methods A and B as described above. Nanoparticles with required concentrations $(750,500,325,200,100,10,1$ and $0 \mu \mathrm{g} / \mathrm{mL})$ were prepared in full phenol red-free medium ( $10 \% \mathrm{FBS}, 1 \%$ L-glutamate, $1 \%$ antibiotic/antimitotic) (see Supplementary information).
RAW 264.7 macrophages of passages $10-15$ were seeded in a 96-well plate at a density of 10,000 cells/well and cultured in DMEM medium containing 10\% FBS, $1 \%$ antibiotic/antimitotic solution, and $1 \%$ L-glutamate and incubated under standard sterile conditions for cell culture $\left(5 \% \mathrm{CO}_{2}, 37{ }^{\circ} \mathrm{C}\right)$ until $70 \%$ confluency. The medium was then removed and the cells were washed with PBS. The cells were then incubated with nanoparticles in full phenol-red free DMEM in standard conditions for cell culture for $0,1,2,4,8,16$ and $24 \mathrm{~h}$. At the completion of the incubation, the cells were washed with PBS and incubated further for $2 \mathrm{~h}$ in serum-free medium containing MTS 5\% $(v / v)$. Cell viability was measured colourimetrically using the conversion of MTS to a soluble coloured formazan. The absorbance readings were acquired with a Synergy2 Biotek plate reader using Gen5 software. The quantity of formazan produced as measured by the absorbance at $490 \mathrm{~nm}$ is proportional to both the number and the metabolic activity of living cells in culture. Cell viability measurements were normalised by the amount of total protein content in each well. Total protein content was quantified using the Quantipro BCA assay kit. Briefly, the cells were washed with PBS, and incubated for $15 \mathrm{~min}$, in $100 \mu \mathrm{L}$ cell lysis buffer ( $0.5 \%$ Triton X-100 in PBS), to which $100 \mu \mathrm{L}$ of Quantipro solution (prepared following the instructions of the manufacturer) was added. After $2 \mathrm{~h}$ incubation at $37^{\circ} \mathrm{C}$, the absorbance was recorded. Cell viability was expressed as the ratio of the absorbance reading for nanoparticle treated cells to that for control non-treated cells.

\subsubsection{Quantification of cellular uptake (fluorimetry)}

RITC-labelled chitosan samples were incorporated in nanoparticle preparation methods A and B to highlight the effect of the preparative procedures, chitosan molecular weight and surface chemistry on the cellular fate of nanoparticles. Following the same procedure as previously described for cell viability studies, the uptake experiments were performed on concentrations ranging from 10 to $250 \mu \mathrm{g} /$ $\mathrm{mL}$ of nanoparticles in full phenol red-free DMEM medium. After specified incubation times $(1,2,4,8,16$ and $24 \mathrm{~h})$, the supernatant solution was removed and the cells were washed three times with PBS and lysed with $100 \mu \mathrm{L}$ of $0.5 \%$ Triton X-100 in $0.2 \mathrm{M} \mathrm{NaOH}$. The amount of membrane bound and internalised nanoparticles was estimated on the basis of the fluorescence of the cell lysates $\left(\lambda_{\mathrm{ex}}=540 \mathrm{~nm}\right.$; $\lambda_{\mathrm{em}}=620 \mathrm{~nm}$ ); nanoparticles dispersed in cell lysates were used to provide a calibration for the fluorescence data. The amount of internalised nanoparticles was normalised by the total protein content, which was quantified using the Quantipro BCA assay kit as described previously. For Michaelis-Menten fitting, the amount of nanoparticles internalised after 2 and $8 \mathrm{~h}$ was divided by the exposure time to respectively provide an initial uptake rate and an overall uptake rate.

\subsubsection{Intracellular localization}

RAW 264.7 macrophages in full DMEM medium were seeded in slide-flasks at a density of 300,000 cells per flask and incubated for $24 \mathrm{~h}$ in standard conditions for cell culture. The medium was then removed and the cells were washed with PBS. The cells were then incubated with nanoparticles in full phenol red-free DMEM at a final concentration of $250 \mu \mathrm{g} / \mathrm{mL}$ for $4 \mathrm{~h}$. At the completion of incubation, the medium was discarded and cells were washed with PBS. Cells were then incubated with $0.2 \%$ wt. trypan blue solution for $1 \mathrm{~min}$ at room temperature and washed further three times with PBS. LysoTracker Green (100 nM) in plain phenol red-free DMEM was then incubated with the cells for $10 \mathrm{~min}$ in standard conditions for cell culture. The medium was carefully discarded and the cells were washed with PBS and fixed with $4 \%$ wt. paraformaldehyde in PBS for $30 \mathrm{~min}$ at room temperature. Fixed cells were washed with PBS and incubated with DAPI for nuclei staining. Cells were then washed with PBS and mounted using an anti-fade mounting gel. The slides were observed under a microscope (Delta Vision RT deconvolution microscope, Applied Precision, Issaquah, USA) using a $60 \times / 1.42$ Plan Apo objective and 360/475 nm, 490/ $528 \mathrm{~nm}$ and 555/617 nm filter sets (Chroma 8600v2/89000, Chroma Technology, USA). The images were acquired using a Coolsnap HQ (Photometrics, Tuscan, USA) camera at a resolution of $512 \times 512$ pixels per inch with a $\mathrm{Z}$ optical spacing of $0.2 \mathrm{~mm}$. Softworx software was used to deconvolute the raw images.

\subsubsection{Mechanism of nanoparticle uptake}

The mechanism of nanoparticle internalization was studied by measuring the relative cellular uptake of fluorescent nanoparticles in RAW 264.7 macrophages after the incubation of cells with a small library of selective inhibitors of different endocytosis mechanisms: cells were treated with each inhibitor before being incubated with the nanoparticles, and afterwards the fluorescence emission of cell lysates was measured. The relative uptake of nanoparticles was expressed as the ratio of the florescence reading for endocytic inhibitor treated cells to that for control non-treated cells. Macrophages were seeded in 96 well-plate and incubated as described in the previous section. Cells were pre-incubated for $30 \mathrm{~min}$ with plain DMEM medium containing (inhibitors) cytochalasin D $(1 \mu \mathrm{m})$, filipin $(5 \mu \mathrm{g} / \mathrm{mL})$, nocodazole $(0.1 \mu \mathrm{g} / \mathrm{mL})$, bafilomycin A1 $(200 \mathrm{~nm})$, chlorpromazine $(65 \mu \mathrm{g} / \mathrm{mL})$, sucrose $(0.45 \mathrm{~m})$ or sodium azide $(10 \mathrm{~mm})$, or for $1 \mathrm{~h}$ with plain DMEM medium containing (inhibitors) EIPA $(100 \mu \mathrm{M})$ or anti-CD44 antibody [KM81] $(20 \mu \mathrm{g} / \mathrm{mL})$. The medium was then discarded and the cells were gently washed with PBS, and further incubated for $2 \mathrm{~h}$ with full phenol red-free DMEM containing nanoparticles at a final concentration of $250 \mu \mathrm{g} / \mathrm{mL}$. The cells were then washed with ice-cold PBS and lysed with $100 \mu \mathrm{L}$ of $0.5 \%$ Triton $\mathrm{X}-100$ in $0.2 \mathrm{M} \mathrm{NaOH}$ for $15 \mathrm{~min}$ at room temperature. Fluorescence readings and BCA assay were carried out as described previously. 


\section{Results and discussion}

\subsection{Nanoparticle characterisation}

\subsubsection{Effect of chitosan molecular weight (method A)}

The dimension of CS-TPP (uncoated) nanoparticles increased with increasing chitosan molecular weight (Table 2, top); this effect is ascribed to a less effective cross-linking action of TPP (gel point reached at a lower TPP content) for larger chitosan macromolecules, thus yielding larger but more porous particles for the same chitosan content. This phenomenon has already been shown for chitosan/TPP microparticles, where the TPP content decreases with increasing chitosan molecular weight [26].

All CS-TPP//HA (HA-coated) nanoparticles showed a similar dimension and charge, independently on chitosan molecular weight (Table 2, middle); in relation to their parent particles, this corresponded to a significant size increase for $\operatorname{CS}(25)$, to a negligible change for CS(325) and to a slight decrease for CS(684). We ascribe this effect to the effect of chitosan molecular weight on the nanoparticle structure: HA would hardly penetrate into compact particles, and indeed $\mathrm{CS}(25)-\mathrm{TPP} / / \mathrm{HA}$ showed a crown of loosely bound HA, which is ultimately responsible of the increase in size (Fig. 1, left); on the other hand more porous particles such as CS(684)-TPP//HA may better accommodate the anionic polysaccharide in their internal structure, yielding no apparent external crown and a more crosslinked and hence shrunken core (Fig. 1, right); a more comprehensive analysis of particle morphology is the subject of a forthcoming publication. However, although present in a different morphology, HA will dictate both surface composition and charge in all cases.

Alginate has twice the charge density of HA and correspondingly should adsorb more rapidly and more efficiently on the cationic CS-TPP nanoparticles. Indeed, CS-TPP//Alg (alginatecoated) nanoparticles showed a higher surface charge, but also a much larger size than the corresponding HA-coated ones (Table 2, bottom). This effect is most likely due to agglomeration during coating, as a consequence of the increased attraction between partially coated particles.

\subsubsection{Effect of preparative method (method $A$ vs. method B)}

We have compared the two preparative methods using $\mathrm{CS}(325)$. In a brief summary, the key differences are as follows:

\section{Table 2}

Physical characteristics ${ }^{\mathrm{a}}$ of nanoparticles as a function of chitosan molecular weight $(25,325$ and $684 \mathrm{kDa})$, coating material (HA/alginate) and preparative method (method A/method B)

\begin{tabular}{|c|c|c|c|c|}
\hline $\begin{array}{l}\text { Chitosan MW (kDa)/ } \\
\text { preparative method }\end{array}$ & $\begin{array}{l}\text { CS25/ } \\
\text { method A }\end{array}$ & $\begin{array}{l}\text { CS325/ } \\
\text { method A }\end{array}$ & $\begin{array}{l}\text { CS325/ } \\
\text { method B }\end{array}$ & $\begin{array}{l}\text { CS684/ } \\
\text { method A }\end{array}$ \\
\hline & CS-TPP & & & \\
\hline$Z$-average size $(\mathrm{nm})$ & $144 \pm 28$ & $263 \pm 38$ & $487 \pm 52$ & $330 \pm 47$ \\
\hline $\mathrm{PDI}^{\mathrm{C}}$ & $0.27 \pm 0.01$ & $0.25 \pm 0.02$ & $0.44 \pm 0.02$ & $0.30 \pm 0.01$ \\
\hline$\zeta$ potential $(\mathrm{mV})$ & $\begin{array}{l}+37 \pm 4 \\
\mathbf{C S}-\mathbf{T P P} / / \mathbf{H A}\end{array}$ & $+41 \pm 3$ & $+47 \pm 2$ & $+41 \pm 6$ \\
\hline$Z$-average size $(\mathrm{nm})$ & $317 \pm 5$ & $303 \pm 59$ & $268 \pm 43$ & $292 \pm 7$ \\
\hline $\mathrm{PDI}^{\mathrm{C}}$ & $0.27 \pm 0.01$ & $0.28 \pm 0.02$ & $0.20 \pm 0.02$ & $0.25 \pm 0.03$ \\
\hline$\zeta$ potential $(\mathrm{mV})$ & $\begin{array}{l}-52 \pm 6 \\
\text { CS-TPP//Alg }\end{array}$ & $-58 \pm 2$ & $-39 \pm 1$ & $-53 \pm 4$ \\
\hline$Z$-average size $(\mathrm{nm})$ & $696 \pm 84$ & $730 \pm 95$ & $499 \pm 21$ & $671 \pm 70$ \\
\hline $\mathrm{PDI}^{\mathrm{C}}$ & $0.33 \pm 0.09$ & $0.30 \pm 0.01$ & $0.34 \pm 0.11$ & $0.31 \pm 0.01$ \\
\hline$\zeta$ potential $(\mathrm{mV})$ & $-76 \pm 3$ & $-78 \pm 8$ & $-56 \pm 6$ & $-72 \pm 2$ \\
\hline
\end{tabular}

${ }^{\mathrm{a}}$ Measurements performed on $250 \mu \mathrm{g} / \mathrm{mL}$ nanoparticle dispersions in deionised water.

$\mathrm{b}$ Using method $\mathrm{B}$, the CS-TPP nanoparticles were prepared at $\mathrm{pH}=4$ in deionised water and the resulting, non-dialysed dispersions were measured at that $\mathrm{pH}$. The CS-TPP//HA and Alg nanoparticles were prepared at $\mathrm{pH}=7.2$ in deionised water and the resulting, non-dialysed dispersions were measured at that $\mathrm{pH}$.

c PDI: polydispersity index. It is calculated in a scale 0 (monodisperse distribution) to 1 (very broad distribution). method $\mathrm{A}-\mathrm{pH}=5$ for both chitosan and TPP (charge $=-3$ ), the two solutions are rapidly mixed because one is injected into the other. Method $\mathrm{B}-$ chitosan at $\mathrm{pH}=4$ (more positively charged) and TPP at $\mathrm{pH}=6.5-7$ (charge $\approx-4$ ); one solution (TPP) is added dropwise into the other, which may result in a kinetically controlled process; no dialysis. The conditions of method A are supposed to provide smaller and possibly more compact nanoparticles because of slower complexation (reduced charge density in both partners) but better mixing; those of method $\mathrm{B}$ were designed to provide a more rapid complexation, possibly leading to larger and more porous objects, and an easier aseptic process.

Indeed, the CS-TPP nanoparticles produced through method B were considerably larger and with a broader size distribution than those obtained through method A (Table 2). On the other hand, they considerably shrunk upon HA coating and produced smaller and less negatively charged objects than their method A counterparts; this effect is possibly a consequence of the higher porosity of method B particles, which would allow polyanions to better diffuse into their bulk, further cross-linking and thus shrinking them. However, we cannot exclude an osmotically-driven shrinkage due to the presence of excess (free) polyanions in the medium, since particles prepared through method B are not purified via dialysis.

Finally, it is noteworthy that also for method B nanoparticles the use of the more negatively charged alginate vs. that of HA likely caused nanoparticle agglomeration.

\subsubsection{Effect of medium}

In cell culture medium (DMEM supplemented with 10\% FBS), all coated nanoparticles considerably shrunk. This effect is wellknown [22] and stems from a reduced nanoparticle swelling due to the increased external osmotic pressure.

For method A the size reduction (compare top and bottom graphs in Fig. 2) was most significant for alginate-coated nanoparticles, whose agglomerated structure would allow much shrinkage to occur between individual particles.

However, all method A nanoparticles showed a comparable final size in cell culture medium, with the majority of the distribution comprised between 100 and $400 \mathrm{~nm}$.

On the other hand, method B nanoparticles shrunk to significantly lower values (Fig. 3; in no case the contribution of $<100 \mathrm{~nm}$ nanoparticles is negligible), which would confirm them to have a looser, more porous internal structure. For any comparison of their effects on cells, it is therefore important to note that method B nanoparticles may differ because of morphological, structural but also dimensional factors.

\subsection{Cellular interactions}

\subsubsection{Effects on macrophage metabolic activity (cytotoxicity)}

We have studied the effect of nanoparticles on the activity of RAW 264.7 macrophages, a cell line with high sensitivity to potentially toxic chemicals [27,28], as a function of nanoparticle concentration, time of exposure, chitosan molecular weight, nature of the anionic polysaccharide and preparative method. This analysis was performed by measuring the macrophage mitochondrial reductase activity (MTS assay) normalised by the cell protein content (BCA assay), thus providing an assessment of the average metabolic activity per cell as a function of the nanoparticle exposure (Fig. 4).

First, no significant difference was recorded for any method A nanoparticles, independently from chitosan molecular weight and from the nature of the coating (either HA or alginate): the macrophages showed no significant reduction in metabolic activity (viability) upon exposure to nanoparticles for concentrations up to $750 \mu \mathrm{g} / \mathrm{mL}$ and for times up to $24 \mathrm{~h}$ (Fig. 4, A-F). The absence of a 

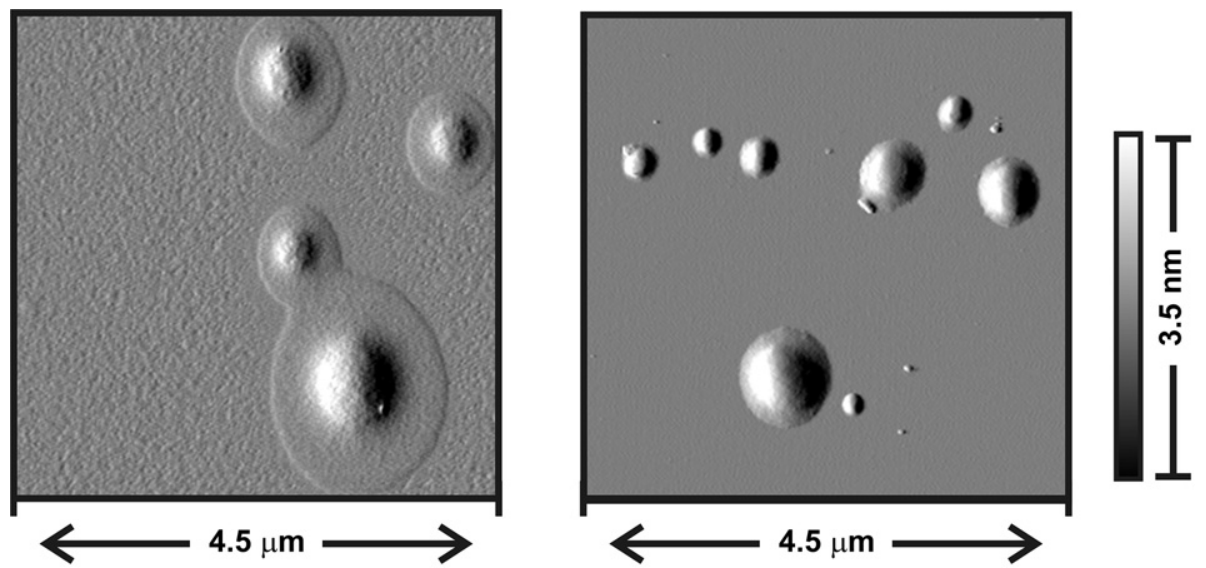

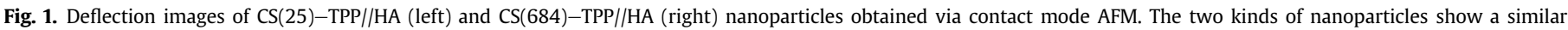

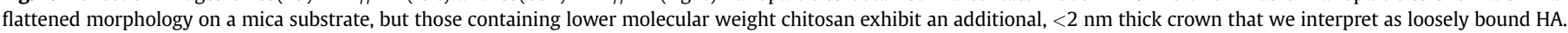

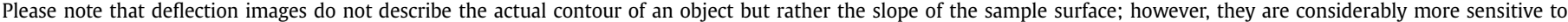

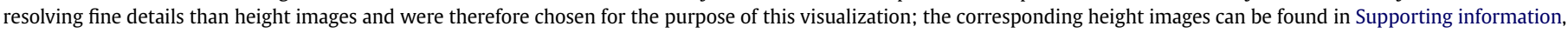
Fig. 1SI.

chitosan molecular weight dependency is not surprising, since this result has also been recorded for uncoated nanoparticles [29].

Since uncoated chitosan-TPP nanoparticles were reported to significantly reduce the viability of the less sensitive J774 macrophages at $300 \mu \mathrm{g} / \mathrm{mL}(24 \mathrm{~h})$ [22], the negligible toxicity of the coated particles suggests that for all chitosan molecular weights, both anionic polysaccharides effectively shielded the underlying chitosan core.

On the other hand, nanoparticles produced with method B showed a rather high toxicity, which depended both on the dose and on the exposure time (Fig. 4, G-H); at $24 \mathrm{~h} \mathrm{HA}$ - and Alg-coated nanoparticles yielding IC50 values of 270 and $480 \mu \mathrm{g} / \mathrm{mL}$, respectively. Method B particles showed larger shrinkage in media and a considerably lower (less negative) $\zeta$ potential; these points would indicate larger porosity and lower exposure of the anionic polysaccharides and/or possible exposure of chitosan, which could be the cause of the increased toxicity. It is noteworthy that HAcoated nanoparticles caused a stronger reduction in cell viability than the alginate-coated ones, which could possibly be due to a more efficient internalisation.

\subsubsection{Kinetics of nanoparticle uptake}

The uptake of nanoparticles was evaluated by measuring the fluorescence of cell lysates (normalised against the protein content)
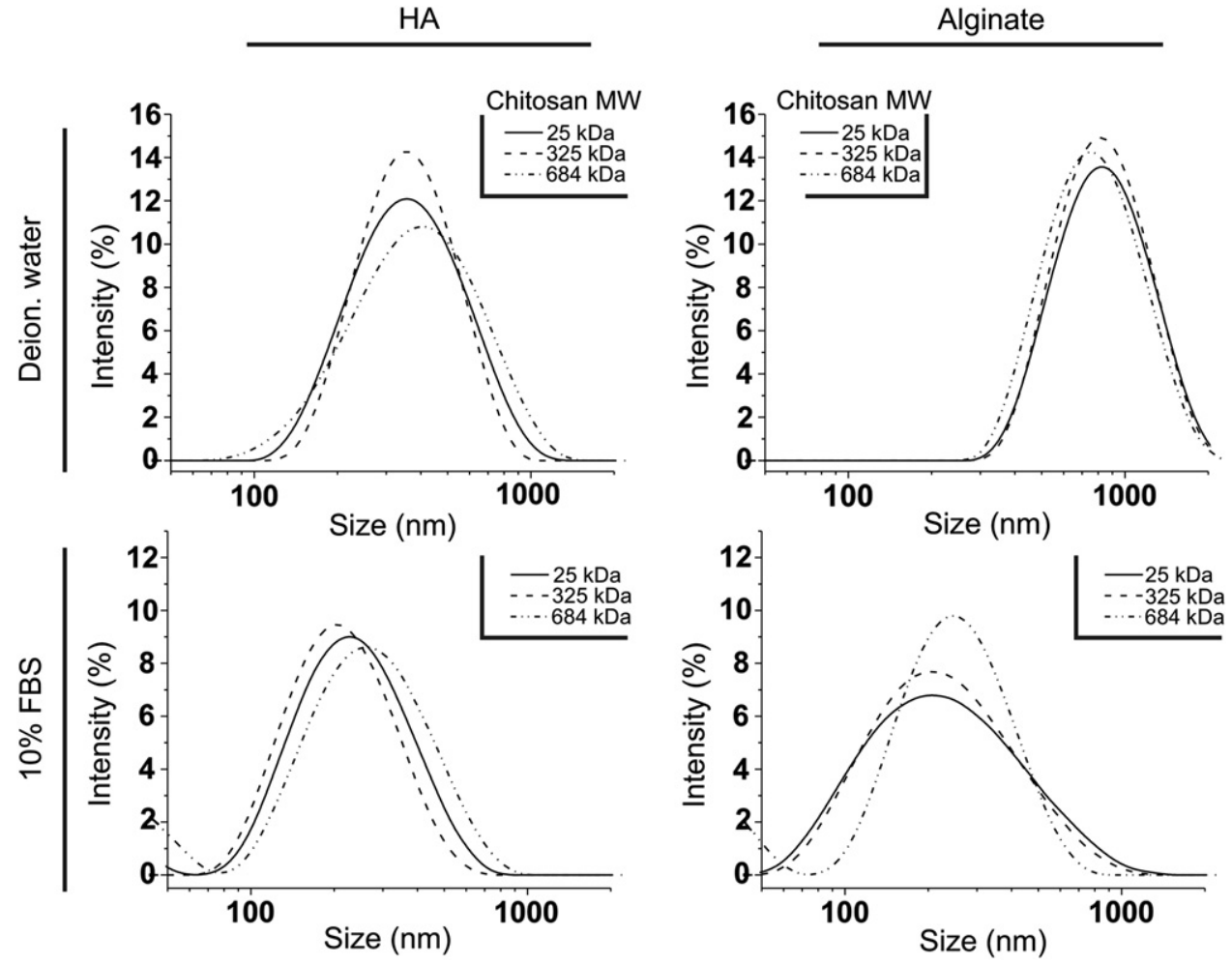

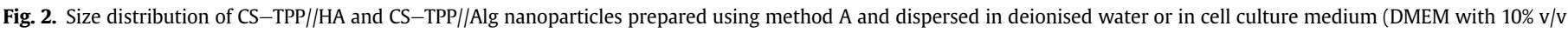
FBS). Nanoparticle concentration: $250 \mu \mathrm{g} / \mathrm{mL}$. Please note that the increase in scattering intensity below $70 \mathrm{~nm}$ is due to FBS proteins. 
HA
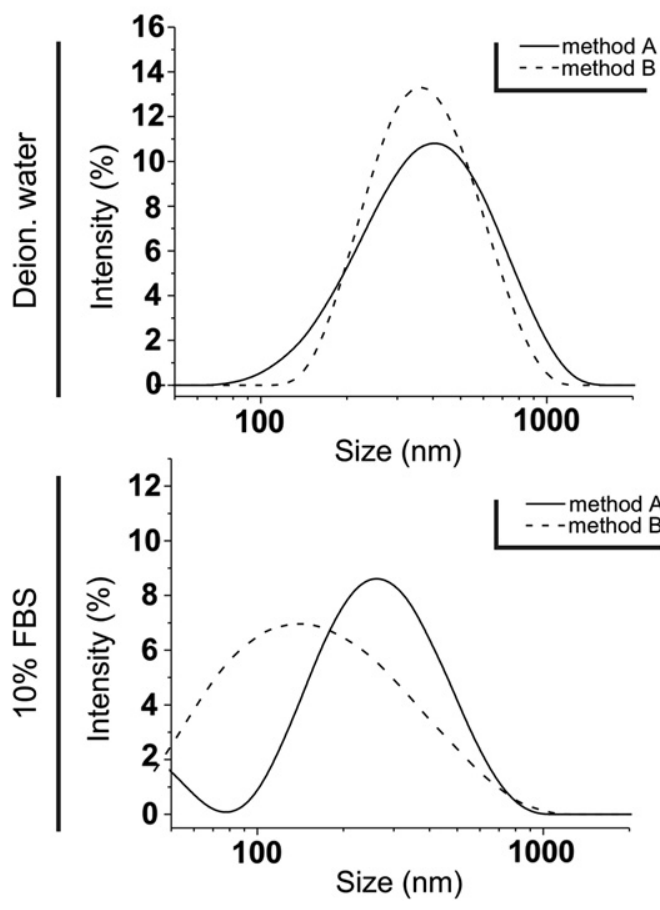

Alginate
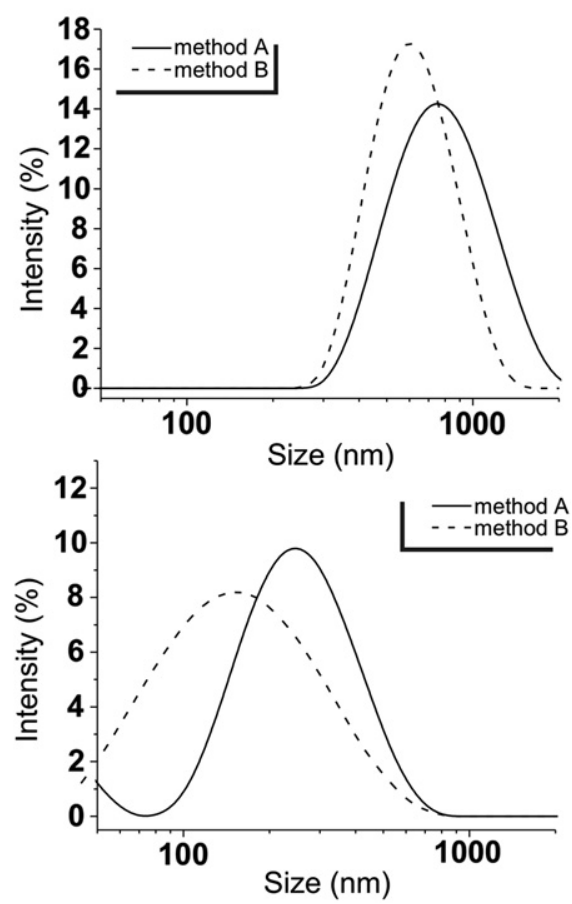

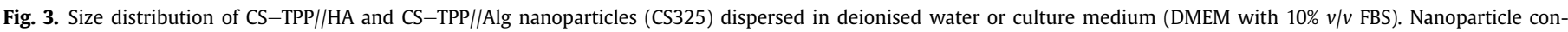
centration: $250 \mu \mathrm{g} / \mathrm{mL}$. Please note that the increase in scattering intensity below $70 \mathrm{~nm}$ is due to FBS proteins.

as a function of nanoparticle concentration, time of exposure, chitosan molecular weight, nature of the anionic polysaccharide and preparative method (Fig. 5). It is noteworthy that this analysis does not allow discrimination between intracellular and surface-bound materials. In all cases, the uptake increased with incubation time and reached a plateau after $8 \mathrm{~h}$, as previously recorded for HAcoated CS-TPP nanoparticles using J774.2 macrophages [22]; please note that in this study we have used the more active RAW 264.7 macrophages, which show a considerably higher nanoparticle uptake (hundreds vs. tens of $\mu \mathrm{g} / \mathrm{mg}$ of protein).

The presence of a plateau suggests an uptake based on a saturable cell receptor, which for HA-based systems has been hypothesised to be the slowly represented CD44 [13]. After binding, CD44 is internalised and then degraded with its ligands; it generally takes $24-48 \mathrm{~h}$ for the cell to represent it again, thus during this time window the capacity of CD44-mediated uptake will considerably diminish $[13,22]$. For alginate-coated nanoparticles, we can only speculate the involvement of a similarly saturable scavenging receptor.

We have first focused on the analysis of the uptake at saturation.

The plateau values increased with increasing nanoparticle concentration, although slowly (a 25-fold increase in concentration corresponded to a 1.5-4.5-fold increase in uptake). This dependency suggests the occurrence of a variable mode of binding: a higher particle concentration may lead to a lower number of clustered receptors per particle and thus a larger uptake per cell (the number of receptors per cell being assumed constant).

HA-coated nanoparticles always showed 20-70\% higher saturation values than alginate-coated ones; this suggests a somewhat higher efficiency for the HA receptor than the putative alginate receptor.

The highest saturation values were recorded for high molecular weight (684 kDa) chitosan nanoparticles (compare Fig. 5, E-F with $A-B$ ). This effect is possibly related to the deeper penetration of the polyanions in these particles, which would reduce their accessibility and therefore determine a lower number of interaction sites per particle, that is, a larger number of particles per cell is allowed; however, we cannot completely exclude some direct exposure of chitosan, which can be internalised through the mannose receptor in macrophages [30], as well as in other cell types [31].

The plateau uptake of method B nanoparticles (Fig. 5, G and H) was particularly low, which could be due to the presence of free (=in solution, unbound) HA or alginate competing with nanoparticles for the same cell receptors. However, even if the internalisation experiments were conducted under the conditions of nanoparticle concentrations/exposure time compatible with untouched viability, we cannot completely exclude effects due to reduction of macrophage metabolic activity.

In order to gather additional quantitative information on the binding kinetics, we have studied how nanoparticle uptake at a given time depended on nanoparticle concentration; the shape of the corresponding curves was strongly influenced by the chitosan molecular weight (Fig. 6, left) and by the preparative method (Fig. 6, right).

The uptake after 2 and $8 \mathrm{~h}$ was respectively used to calculate an initial and an overall uptake rate, whose concentration dependency was fitted using a Michaelis-Menten model [19,25]. This treatment provides an asymptotic internalisation rate at high particle concentration $\left(V_{\max }\right)$ and a value inversely related to the average nanoparticle affinity for macrophages $\left(K_{m}\right)$ (see Supplementary information, Figs. 2SI and 3SI). Despite its probably excessive simplicity, this model has been widely applied to study a range of receptor-mediated processes, e.g. the internalisation of proteins $[32,33]$ or bile salt/drug complexes [34].

Either obtained for the initial phase $(0-2 \mathrm{~h})$ or for the overall kinetics $(0-8 \mathrm{~h})$ the results are substantially analogous (Table 3 ) and indicate three trends: 

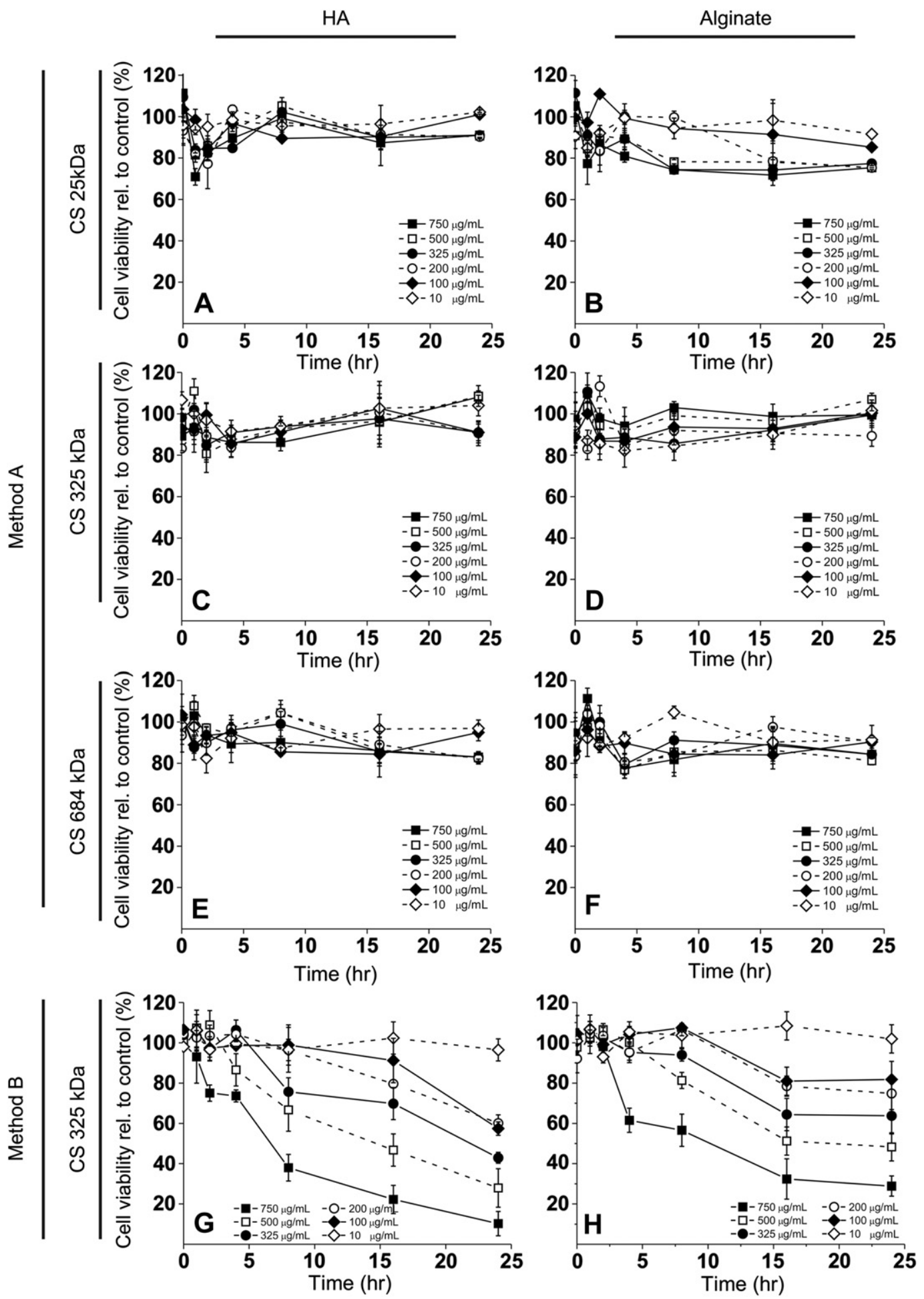

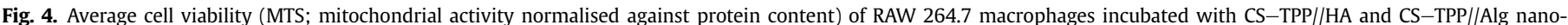

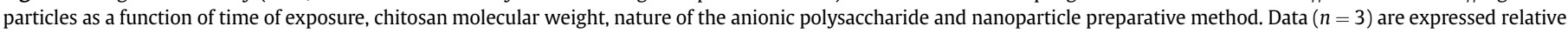
to control experiments.

First, HA-coated particles showed a $10-50 \%$ larger $V_{\max }$ and a 20-80\% higher affinity (lower $K_{m}$ ) than alginate-coated ones. The difference in $V_{\max }$ is probably due to the availability of a different number of receptors for the two polysaccharides. The difference in affinity can be due to a different clustering behaviour of HA and alginate receptors: the latter ones may be less prone to cluster around the same nanoparticle, decreasing the scavenging efficiency (affinity) at low particle concentration.

Second, the dependency of uptake kinetics on chitosan molecular weight can be explained in a similar fashion, with the accessibility of HA or alginate being reduced in high molecular weight chitosan particles and therefore allowing for more internalisation 

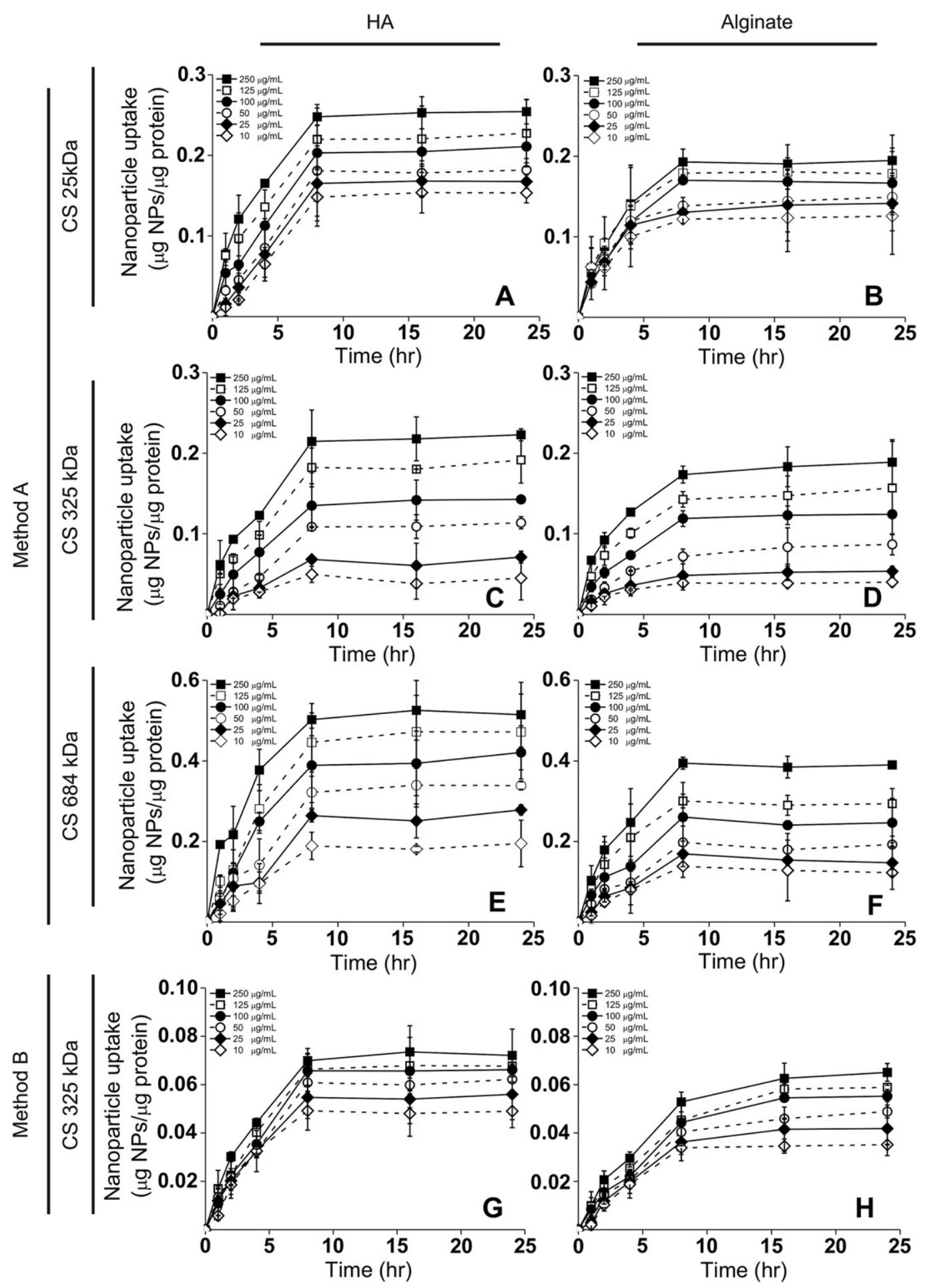

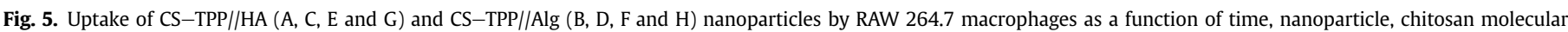

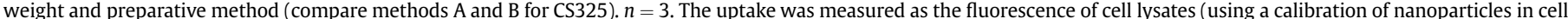

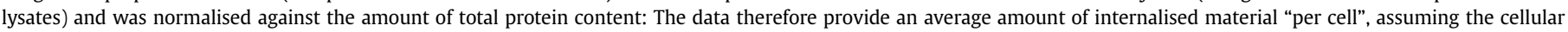

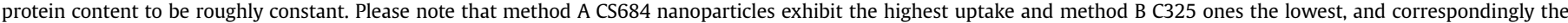
vertical scales are not the same as for the other nanoparticle types.

points (higher $V_{\max }$ ) with lower affinity (higher $K_{m}$ ). An explanation for the much reduced affinity of CS(325)-TPP coated nanoparticles can only be tentative and invoke a tighter binding of the anionic polysaccharides: CS325 has the highest content of acetyl groups that, by promoting hydrophobic association, may also increase the local density of the cationic groups.
Third, method B nanoparticles were internalised with a slower kinetics (3-5 time smaller $V_{\max }$ ) but much higher affinity (10-40 times lower $K_{m}$ ) than those with identical composition obtained with method A. As previously mentioned, their uptake kinetics can be heavily influenced by the competition with excess of (nonbound) polyanions in solution, which may allow internalisation 

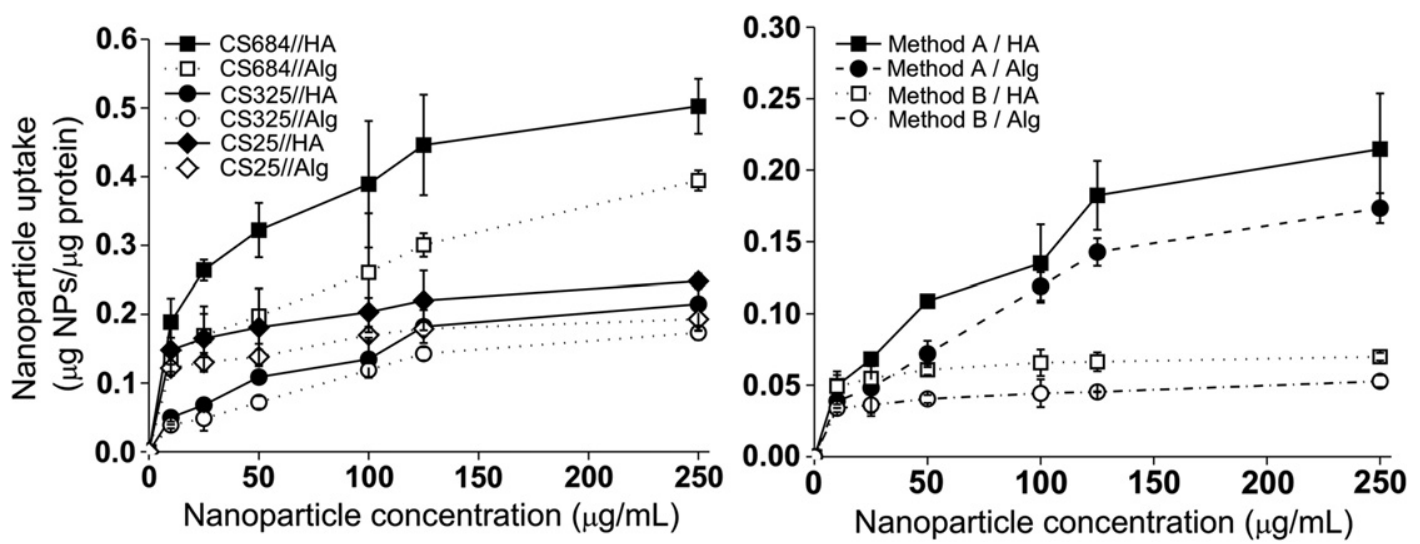

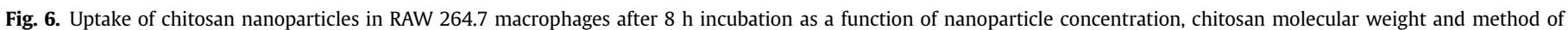
preparation (right).

only of particles with affinity higher than that of free HA/alginate; however, the considerably smaller diameter of most particles (Fig. 3, bottom graphs) may also facilitate receptor clustering leading to higher affinity.

\subsubsection{Mechanism of internalisation}

As recently reviewed [35], the use of selective endocytic inhibitors can be applied to assess the mechanism of internalization of nanomaterials. Here, we have quantitatively assessed the effect of inhibitors by first exposing RAW 264.7 macrophages to them and then measuring the fluorescence of cell lysates after a $2 \mathrm{~h}$ incubation with the nanoparticles (Fig. 7).

It is noteworthy that chitosan molecular weight and method of preparation did not appear to affect the mechanism of internalisation, which on the contrary seemed to depend on the chemistry of the adsorbed polyanion.

Sodium azide, cytochalasin D, nocodazole and bafilomycin A1 were used as positive controls: by interfering respectively with all energy dependent processes [36], F-actin polymerization microtubule formation/active vesicular transport $[37,38]$ and endosomal acidification/receptor recycling [13,39]. They are general inhibitors of all or most forms of endocytosis and intracellular trafficking. Sodium azide and cytochalasin D very significantly reduced the internalisation of all kinds of particles $(20-40 \%$ values of the control), showing the uptake to be an active, endocytic process. The lower influence of nocodazole $(10-15 \%$ and $15-23 \%$ reduction in uptake for HA-coated and Alg-coated nanoparticles, respectively) and bafilomycin A1 (35-50\% and $20-30 \%$ reduction in uptake for HA-coated and Alg-coated nanoparticles respectively) is probably

Table 3

Kinetic parameters (Michaelis-Menten model) for the uptake of CS-TPP//HA and CS-TPP//Alg nanoparticles.

\begin{tabular}{|c|c|c|c|c|c|}
\hline \multirow[t]{2}{*}{$\begin{array}{l}\text { Preparative } \\
\text { method }\end{array}$} & \multirow[t]{2}{*}{ Nanoparticles } & \multicolumn{2}{|c|}{$\begin{array}{l}\text { Michaelis-Menten } \\
\text { fitting at } 2 \mathrm{~h}\end{array}$} & \multicolumn{2}{|c|}{$\begin{array}{l}\text { Michaelis-Menten } \\
\text { fitting at } 8 \mathrm{~h}\end{array}$} \\
\hline & & $\begin{array}{l}V_{\max } \\
(\mu \mathrm{g} / \mathrm{mg} \mathrm{h})\end{array}$ & $\begin{array}{l}K_{m} \\
(\mu \mathrm{g} / \mathrm{mL})\end{array}$ & $\begin{array}{l}V_{\max } \\
(\mu \mathrm{g} / \mathrm{mg} \mathrm{h})\end{array}$ & $\begin{array}{l}K_{m} \\
(\mu \mathrm{g} / \mathrm{mL})\end{array}$ \\
\hline \multirow[t]{6}{*}{ A } & $\mathrm{CS}(684)-\mathrm{TPP} / / \mathrm{HA}$ & $114 \pm 21$ & $57 \pm 30$ & $65 \pm 4$ & $25 \pm 5$ \\
\hline & CS(684)-TPP//Alg & $110 \pm 15$ & $72 \pm 25$ & $51.5 \pm 5$ & $33 \pm 11$ \\
\hline & $\mathrm{CS}(325)-\mathrm{TPP} / / \mathrm{HA}$ & $84 \pm 20$ & $204 \pm 84$ & $35 \pm 4$ & $76 \pm 20$ \\
\hline & CS(325)-TPP//Alg & $70 \pm 14$ & $136 \pm 53$ & $25 \pm 3.4$ & $84 \pm 27$ \\
\hline & $\mathrm{CS}(25)-\mathrm{TPP} / / \mathrm{HA}$ & $94 \pm 17$ & $49 \pm 13$ & $27 \pm 0.5$ & $4.5 \pm 0.6$ \\
\hline & $\mathrm{CS}(25)-\mathrm{TPP} / / \mathrm{Alg}$ & $42 \pm 3$ & $5 \pm 2$ & $21 \pm 1$ & $5.6 \pm 2$ \\
\hline \multirow[t]{2}{*}{ B } & $\mathrm{CS}(325)-\mathrm{TPP} / / \mathrm{HA}$ & $13 \pm 1$ & $5 \pm 2.7$ & $8.6 \pm 0.2$ & $4.7 \pm 1$ \\
\hline & CS(325)-TPP//Alg & $9.7 \pm 1$ & $13 \pm 4.2$ & $6.4 \pm 0.2$ & $8.8 \pm 2$ \\
\hline
\end{tabular}

ascribable to the relatively short time of the test, which allows only for a limited extent of intracellular trafficking; however, their clear inhibitory effect indicates that all particles are likely trafficked in endosomes (nocodazole) and that their endocytosis is probably a receptor-mediated process jammed by inhibition of acidification (bafilomycin). Indeed, fluorescence microscopy showed a significant co-localisation of the nanoparticles with late endosomes/lysosomes (Fig. 8). It is noteworthy that the fluorescence associated to chitosan typically covered larger areas around those associated to Lysotracker fluorescence (see the red halos around the yellow dots in the merged pictures of Fig. 8), which is a sign of lysosomal escape.

Chlorpromazine and hypertonic sucrose $(0.45 \mathrm{~m})$ interfere with the formation of clathrin-coated pits $[40,41]$ and are therefore widely considered as inhibitors of the clathrin-mediated endocytosis. In no case, they appeared to reduce uptake, suggesting, therefore, no involvement of clathrin in the internalisation process. It is worth pointing out that this may be a cell-specific process. For example, RAW 264.7 macrophages have shown clathrin-dependent internalisation of nanomaterials such as superparamagnetic iron oxide nanoparticles [42], while other endo/phagocytic processes are not affected by clathrin inhibition [43]. On the other hand, in a previous study by our group, J774.2 macrophages showed a 20$30 \%$ reduction of HA-coated CS(477)-TPP nanoparticles internalisation with clathrin inhibition via hypertonic sucrose or potassium-free buffer [22], a difference that we are inclined to ascribe to the different endocytic behaviour of the two cell lines.

Pre-incubation with 5-(N-ethyl-N-isopropyl)amiloride (EIPA), which suppresses endocytosis via macropinocytosis [13,44], did not affect the internalisation of HA-coated nanoparticles, while resulted in a $10-20 \%$ decrease in alginate-coated ones, with no statistically significant difference attributable to chitosan molecular weight or method of preparation. Due to this negligible or relatively little effect, macropinocytosis was concluded not to be a major internalisation route for any of the nanoparticle formulations.

Filipin is a cholesterol-sequestrant that inhibits lipid raftdependent internalisation processes such as caveolae-mediated endocytosis $[41,45]$. Filipin had no effect on the internalisation of HA-coated nanoparticles and caused a rather slight decrease in alginate-coated nanoparticles (alginate-coated nanoparticles uptake was reduced by 16 and $10 \%$ for 25 and $684 \mathrm{kDa}$ chitosan, respectively), which possibly suggests some involvement of lipid raft-mediated endocytosis in the uptake of alginate-coated nanoparticles.

Finally, the use of a mouse anti-CD44 antibody [KM81] produced a $65 \%$ reduction in the uptake of HA-coated nanoparticles 
$\mathrm{HA}$
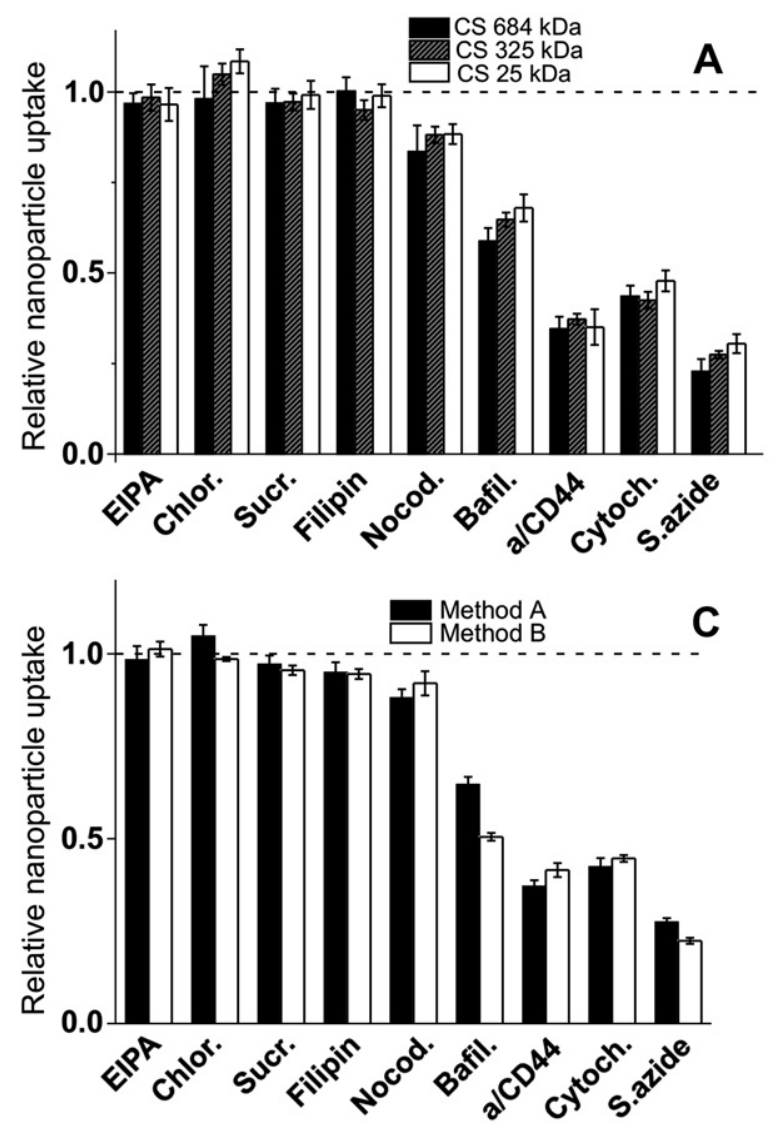

Alginate
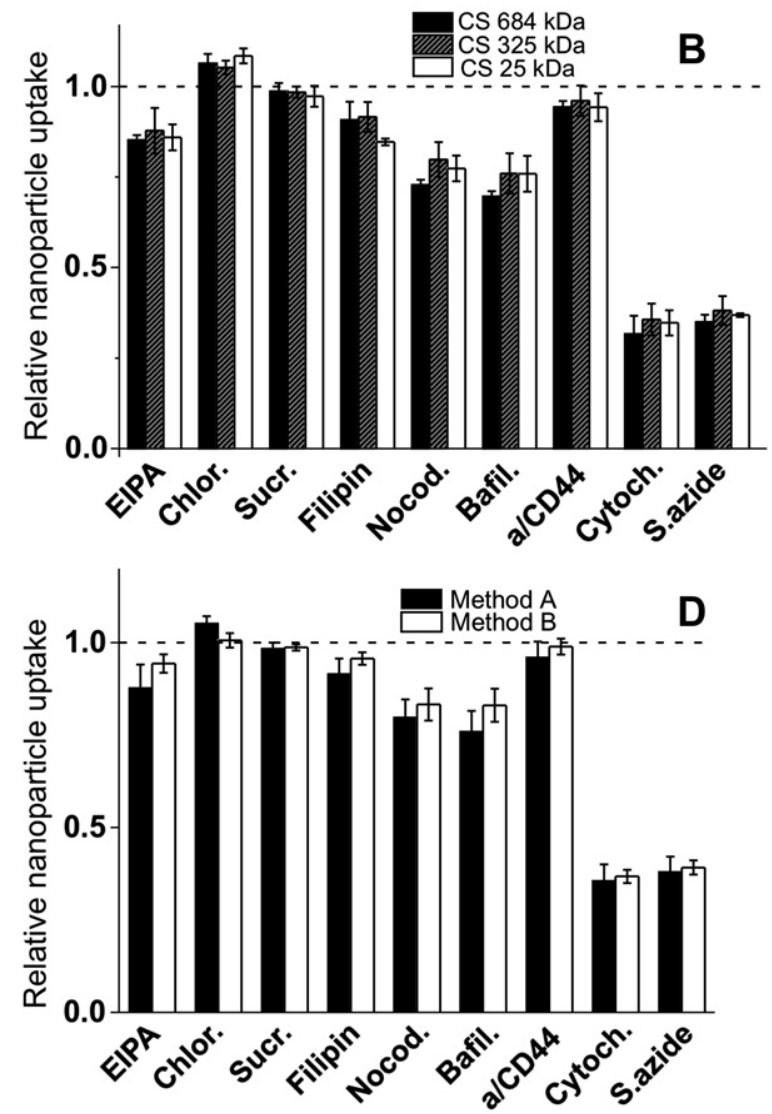

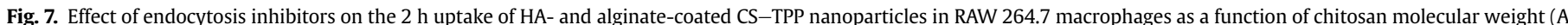

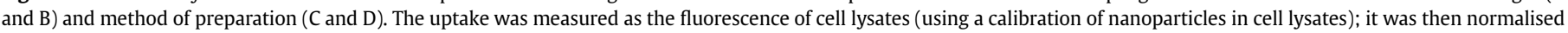
against the amount of total cellular protein content and expressed in relation to control experiments performed without inhibitors. $n=3$.

while only marginally affected $(-5 \%)$ the internalisation of alginate-coated ones. This result finally proved that the internalisation of the HA-coated particles is a CD44-mediated process.

From the above analysis it appears that HA-coated nanoparticles were internalised in RAW 264.7 macrophages through a
CD44-mediated process leading to acidified late endosomes. The precise nature of the internalisation mechanism is not completely clarified and shows differences from that in J774 macrophages, which was at least partially clathrin-dependent [22].

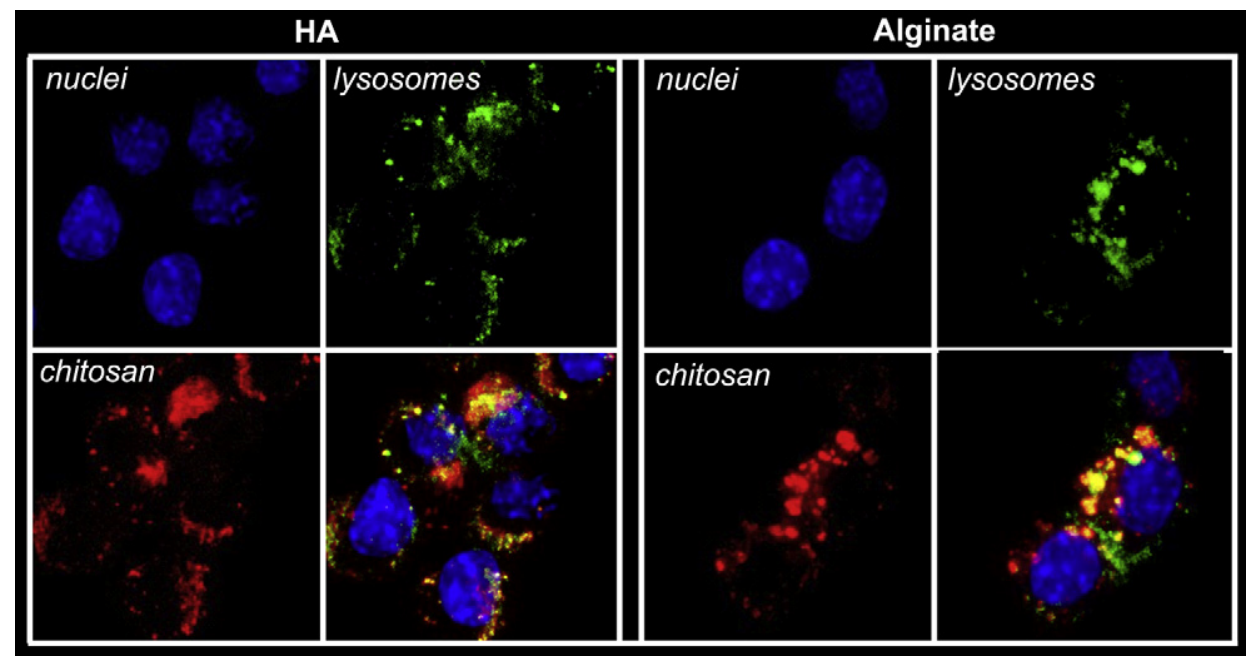

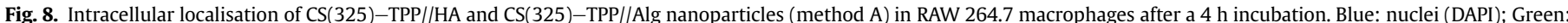

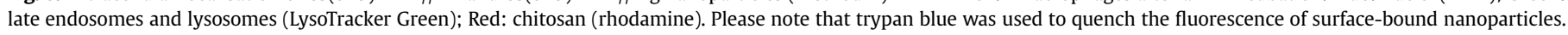
(For interpretation of the references to colour in this figure legend, the reader is referred to the web version of this article.) 


\section{Conclusions}

In this study, we believe to have demonstrated that, firstly, the internalisation of HA-coated nanoparticles is a CD44-mediated process; their similar kinetic profile suggests that the uptake of alginate-coated nanoparticles is also a process mediated by a saturable (scavenging) receptor. Secondly, an identical ligand, e.g. $\mathrm{HA}$ with the same molecular weight, can be presented in a different arrangement on the nanoparticle surface, due to morphological differences arising, for example, from the method of preparation, or from the use of chitosan with different molecular weights. These differences do not appear to affect the nature of the uptake, which for HA-coated nanoparticles appear to be still based on binding to CD44. On the other hand, the different ligand presentation seems to have major effects on the mode of interactions affecting affinity and speed of uptake and also cytotoxicity. We believe this to be a consequence of the limited number and of the slow representation of the internalisation receptors; under these conditions, a lower number of receptors would cluster around nanoparticles with poorly presented HA resulting in lower affinity but higher overall number of bound particles.

\section{Acknowledgements}

Dr. Peter Käuper and Dr. Carsten Laue (Medipol SA, Lausanne, Switzerland) are gratefully acknowledged for their essential role in the preparation and initial coordination of the study, and Nathanäel Rossi (Medipol SA, Lausanne, Switzerland) for the collaboration in the preparation of method B nanoparticles; Dr. Peter Käuper is in particular thanked for the enthusiasm he has infused. We are also indebted to Dr. Enrique Lallana for the helpful points raised during manuscript revision and to Dr. Francesco Cellesi (School of Pharmacy, University of Manchester, UK) for technical help and additional supervision to Mr. Almalik. Financial support from the Marie Curie Industry-Academia Partnerships and Pathways (IAPP) "Replixcel" project (No 251420) and from a King Abdulaziz City for Science and Technology (KACST) PhD bursary (Mr. Almalik) is acknowledged.

\section{Appendix A. Supplementary data}

Supplementary data related to this article can be found at http:// dx.doi.org/10.1016/j.biomaterials.2013.03.065.

\section{References}

[1] Ghosh SC, Alpay SN, Klostergaard J. Cd44: a validated target for improved delivery of cancer therapeutics. Expert Opin Ther Targets 2012;16:635-50.

[2] Negi LM, Talegaonkar S, Jaggi M, Ahmad FJ, Iqbal Z, Khar RK. Role of cd44 in tumour progression and strategies for targeting. J Drug Target 2012;20: $561-73$.

[3] Coradini D, Pellizzaro C, Miglierini G, Daidone MG, Perbellini A. Hyaluronic acid as drug delivery for sodium butyrate: improvement of the antiproliferative activity on a breast-cancer cell line. Int J Cancer 1999;81:411-6.

[4] Auzenne E, Ghosh SC, Khodadadian M, Rivera B, Farquhar D, Price RE, et al. Hyaluronic acid-paclitaxel: antitumor efficacy against cd44(+) human ovarian carcinoma xenografts. Neoplasia 2007;9:479-86.

[5] Choi KY, Chung H, Min KH, Yoon HY, Kim K, Park JH, et al. Self-assembled hyaluronic acid nanoparticles for active tumor targeting. Biomaterials 2010;31:106-14.

[6] Lee H, Ahn C-H, Park TG. Poly lactic-co-(glycolic acid) -grafted hyaluronic acid copolymer micelle nanoparticles for target-specific delivery of doxorubicin. Macromol Biosci 2009:9:336-42.

[7] Lee H, Mok H, Lee S, Oh Y-K, Park TG. Target-specific intracellular delivery of sirna using degradable hyaluronic acid nanogels. J Control Release 2007;119: 245-52.

[8] Choi KY, Min KH, Yoon HY, Kim K, Park JH, Kwon IC, et al. Pegylation of hyaluronic acid nanoparticles improves tumor targetability in vivo. Biomaterials 2011;32:1880-9.
[9] Choi KY, Saravanakumar G, Park JH, Park K. Hyaluronic acid-based nanocarriers for intracellular targeting: interfacial interactions with proteins in cancer. Colloids Surf B Biointerfaces 2012;99:82-94.

[10] Ossipov DA. Nanostructured hyaluronic acid-based materials for active delivery to cancer. Expert Opin Drug Deliv 2010;7:681-703.

[11] Hyung W, Ko H, Park J, Lim E, Park SB, Park Y-J, et al. Novel hyaluronic acid (ha) coated drug carriers (hcdcs) for human breast cancer treatment. Biotechnol Bioeng 2008;99:442-54.

[12] Coradini D, Zorzet S, Rossin R, Scarlata I, Pellizzaro C, Turrin C, et al. Inhibition of hepatocellular carcinomas in vitro and hepatic metastases in vivo in mice by the histone deacetylase inhibitor ha-but. Clin Cancer Res 2004; 10:4822-30.

[13] Ouasti S, Kingham PJ, Terenghi G, Tirelli N. The cd44/integrins interplay and the significance of receptor binding and re-presentation in the uptake of rgdfunctionalized hyaluronic acid. Biomaterials 2012;33:1120-34.

[14] Pure E, Cuff CA. A crucial role for cd44 in inflammation. Trends Mol Med 2001;7:213-21.

[15] Teder P, Vandivier RW, Jiang DH, Liang JR, Cohn L, Pure E, et al. Resolution of lung inflammation by cd44. Science 2002;296:155-8.

[16] Wolny PM, Banerji S, Gounou C, Brisson AR, Day AJ, Jackson DG, et al. Analysis of cd44-hyaluronan interactions in an artificial membrane system insights into the distinct binding properties of high and low molecular weight hyaluronan. J Biol Chem 2010;285:30170-80.

[17] de la Motte CA, Hascall VC, Drazba J, Bandyopadhyay SK, Strong SA. Mononuclear leukocytes bind to specific hyaluronan structures on colon mucosal smooth muscle cells treated with polyinosinic acid: polycytidylic acid - interalpha-trypsin inhibitor is crucial to structure and function. Am J Pathol 2003; $163: 121-33$

[18] Jokela TA, Lindgren A, Rilla K, Maytin E, Hascall VC, Tammi RH, et al. Induction of hyaluronan cables and monocyte adherence in epidermal keratinocytes. Connect Tissue Res 2008;49:115-9.

[19] Lesley J, Gal I, Mahoney DJ, Cordell MR, Rugg MS, Hyman R, et al. Tsg-6 modulates the interaction between hyaluronan and cell surface cd44. J Biol Chem 2004;279:25745-54.

[20] Ding HM, Ma YQ. Role of physicochemical properties of coating ligands in receptor-mediated endocytosis of nanoparticles. Biomaterials 2012;33: 5798-802

[21] Laroui H, Grossin L, Leonard M, Stoltz JF, Gillet P, Netter P, et al. Hyaluronatecovered nanoparticles for the therapeutic targeting of cartilage. Biomacromolecules 2007;8:3879-85.

[22] Zaki NM, Nasti A, Tirelli N. Nanocarriers for cytoplasmic delivery: cellular uptake and intracellular fate of chitosan and hyaluronic acid-coated chitosan nanoparticles in a phagocytic cell model. Macromol Biosci 2011;11:1747-60.

[23] Nasti A, Zaki NM, de Leonardis P, Ungphaiboon S, Sansongsak P, Rimoli MG, et al. Chitosan/tpp and chitosan/tpp-hyaluronic acid nanoparticles: systematic optimisation of the preparative process and preliminary biological evaluation. Pharm Res 2009;26:1918-30.

[24] Kasaai MR, Arul J, Charlet C. Intrinsic viscosity-molecular weight relationship for chitosan. J Polym Sci Polym Phys 2000;38:2591-8.

[25] Kaeuper P, Laue C, Kauper P. Hydrophilic particles, useful in a composition e.g. pharmaceutical composition and for transport and the concentration of biologically active substances in biological system, comprises chitosan and anionic polysaccharide. WO2007031812-A1; EP1968613-A1; US2008254078-A1.

[26] Ungphaiboon S, Attia D, d'Ayala GG, Sansongsak P, Cellesi F, Tirelli N. Materials for microencapsulation: what toroidal particles ("doughnuts") can do better than spherical beads. Soft Matter 2010;6:4070-83.

[27] Kagan VE, Tyurina YY, Tyurin VA, Konduru NV, Potapovich AI, Osipov AN, et al. Direct and indirect effects of single walled carbon nanotubes on raw 264.7 macrophages: role of iron. Toxicol Lett 2006;165:88-100.

[28] Xia T, Kovochich M, Liong M, Madler L, Gilbert B, Shi HB, et al. Comparison of the mechanism of toxicity of zinc oxide and cerium oxide nanoparticles based on dissolution and oxidative stress properties. ACS Nano 2008;2:2121-34.

[29] Huang M, Khor E, Lim LY. Uptake and cytotoxicity of chitosan molecules and nanoparticles: effects of molecular weight and degree of deacetylation. Pharm Res 2004;21:344-53.

[30] Han YP, Zhao LH, Yu ZJ, Feng J, Yu QQ. Role of mannose receptor in oligochitosan-mediated stimulation of macrophage function. Int Immunopharmacol 2005;5:1533-42.

[31] Douglas KL, Piccirillo CA, Tabrizian M. Cell line-dependent internalization pathways and intracellular trafficking determine transfection efficiency of nanoparticle vectors. Eur J Pharm Biopharm 2008;68:676-87.

[32] Schwartz AL, Fridovich SE, Lodish HF. Kinetics of internalization and recycling of the asialoglycoprotein receptor in a hepatoma-cell line. J Biol Chem 1982;257:4230-7.

[33] Krippendorff BF, Kuester K, Kloft C, Huisinga W. Nonlinear pharmacokinetics of therapeutic proteins resulting from receptor mediated endocytosis. J Pharmacokinet Pharmacodyn 2009;36:239-60.

[34] Ballatori N, Hager DN, Nundy S, Miller DS, Boyer JL. Carrier-mediated uptake of lucifer yellow in skate and rat hepatocytes: a fluid-phase marker revisited. Am J Physiol Gastrointest Liver Physiol 1999;277:G896-904.

[35] Zaki NM, Tirelli N. Gateways for the intracellular access of nanocarriers: a review of receptor-mediated endocytosis mechanisms and of strategies in receptor targeting. Expert Opin Drug Deliv 2010;7:895-913.

[36] Behrens I, Pena AIV, Alonso MJ, Kissel T. Comparative uptake studies of bioadhesive and non-bioadhesive nanoparticles in human intestinal cell lines 
and rats: the effect of mucus on particle adsorption and transport. Pharm Res 2002;19:1185-93.

[37] Goncalves C, Mennesson E, Fuchs R, Gorvel JP, Midoux P, Pichon C. Macropinocytosis of polyplexes and recycling of plasmid via the clathrin-dependent pathway impair the transfection efficiency of human hepatocarcinoma cells. Mol Ther 2004;10:373-85.

[38] van der Aa M, Huth US, Hafele SY, Schubert R, Oosting RS, Mastrobattista E, et al. Cellular uptake of cationic polymer-DNA complexes via caveolae plays a pivotal role in gene transfection in cos-7 cells. Pharm Res 2007:24:1590-8.

[39] Issa MM, Koping-Hoggard M, Tommeraas K, Varum KM, Christensen BE, Strand SP, et al. Targeted gene delivery with trisaccharide-substituted chitosan oligomers in vitro and after lung administration in vivo. J Control Release 2006;115:103-12.

[40] Gotte M, Feugaing DDS, Kresse H. Biglycan is internalized via a chlorpromazine-sensitive route. Cell Mol Biol Lett 2004;9:475-81.
[41] Qaddoumi MG, Gukasyan HJ, Davda J, Labhasetwar V, Kim KJ, Lee VHL. Clathrin and caveolin-1 expression in primary pigmented rabbit conjunctiva epithelial cells: role in plga nanoparticle endocytosis. Mol Vis 2003;9:559-68.

[42] Yang CY, Tai MF, Lin CP, Lu CW, Wang JL, Hsiao JK, et al. Mechanism of cellular uptake and impact of ferucarbotran on macrophage physiology. PLoS One 2011;6.

[43] Tse SML, Furuya W, Gold E, Schreiber AD, Sandvig K, Inman RD, et al. Differential role of actin, clathrin, and dynamin in fc gamma receptor-mediated endocytosis and phagocytosis. J Biol Chem 2003;278:3331-8.

[44] Nakase I, Niwa M, Takeuchi T, Sonomura K, Kawabata N, Koike Y, et al. Cellular uptake of arginine-rich peptides: roles for macropinocytosis and actin rearrangement. Mol Ther 2004;10:1011-22.

[45] Rejman J, Bragonzi A, Conese M. Role of clathrin- and caveolae-mediated endocytosis in gene transfer mediated by lipo- and polyplexes. Mol Ther $2005 ; 12: 468-74$ 